\title{
Design And Implementation Of Ls-Pmsg For Small Scale Hydro Power Plant
}

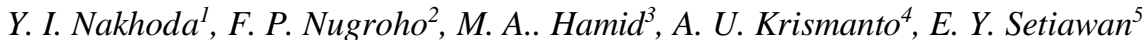 \\ 1,2,3,4 Electrical Engineering Dept, National Institute of Technology Malang \\ ${ }^{5}$ Mechanical Engineering Dept, National Institute of Technology Malang \\ Email:yohanes@lecturer.itn.ac.id
}

\begin{abstract}
In a conventional power system, a synchronous generator characterized by high-speed operating condition has been widely implemented. However, those high-speed synchronous machines are not suitable for a power plant powered by renewable energy (RE) due to the uncertain feature of renewable resources. To overcome this problem, an electrical machine with a low-speed characteristic is required for ensuring stable operation and maintaining the output power of the RE-based distribution generation (DG) unit. In this paper, a low-speed permanent magnet synchronous generator (LS-PMSG) is designed and implemented. To realize low-speed operation capability, the multi-stages permanent magnet synhcronous machine is proposed. The multi-stages machine equipped with two stators and three rotors construction. From the experimental results, it was monitored that output voltage of single rotor of the designed machine was $35 \mathrm{~V}$. Moreover, to increase the output voltage to $50 \mathrm{~V}$, those three rotors can be connected in series.
\end{abstract}

Keyword renewable energy, low-speed, muti-stages permanent magnet synchronous machine.

Paper type Research paper

\section{INTRODUCTION}

The significant increase in population leads to an increase in electrical load. Consequently, the utility must proportionally generate more power to deal with the increase of demand both in urban and remote areas. On the other hand, expanding transmission and distribution networks is a costly option for providing electricity services for the small community in a remote area. Moreover, environmental issues have to be considered in generating electrical power. To solve this problem, a small-scale power plant powered by renewable energy resources such as solar energy, wind and hydro have become main considerations. As a country with an abundant hydro resource, the small-scale hydropower plant has been widely applied and implemented in Indonesia for providing electricity service for the rural community which cannot be reached by distribution network from the utility company. A micro-hydro or even pico-hydro scale power plants have become popular due to its low-price investment and easy to handle features.

Even though small-scale hydropower generation is a reasonable solution for rural area electrification, uncertain condition of water level and continuity of water flow have become major concern in developing those small-scale hydropower generation plant. On the other hand, generally, a permanent magnet synchronous generator with high-speed characteristic mostly implemented in those hydropower generation units. As a result, it is difficult to maintain the output power of the micro or pico-hydropower plant under low-level water and slow water flow conditions. To maintain stability and ensure continuity of electricity supply, a small-scale generator which can be operated efficiently in most of the water level and flows ranges with an acceptable power output

Most of the generator available in the market is the permanent magnet generator with a high-speed characteristic which requires an initial electric power to create a magnetic field [2]. Therefore, it is difficult to implement this type of generator for small scale hydropower plant. A low-speed permanent magnet synchronous generator (LS-PMSG) is considered [3] for this research. The proposed synchronous machines can be operated at a lower speed to maintain the power output under lack of hydropower resource in term of low water level and slow water flow. It is expected that with LS-PMSG, enhancement of power output stability can be maintained in most of the water circumstances throughout the year.

This paper addresses the design and manufacture procedures of LS-PMSG for micro and pico-hydropower plant. Multi-disc LS-PMSG type is selected since it is more efficient and can generate more power. The multi-disc design offers more flexibility in increasing the generator capacity by adding the number of rotor and stator. Moreover, it also can be coupled with various types of turbines without significantly change the output power characteristic of the machine.

\section{DESIGN OF LS-PMSG}

The following section delivers design and manufacture procedures of proposed LS-PMSG involving selections and calculations of the magnetic core, stator, and rotor.

The first step for machine design is determining the operational frequency and nominal speed. Correlation between the rotating speed of stator magnetic field and frequency is given in the following equation 


$$
n_{g}=\frac{120 \times f}{p} \quad r p m
$$

Where $p$ and $n_{g}$ represent the number of poles and the nominal speed of the machine.

It was planned that the proposed LS-PMSG is operated under $50 \mathrm{~Hz}$ nominal frequency and $600 \mathrm{rpm}$ nominal speed. From (1), the number of poles can be determined. Hence, according to the planning design, 10 number of poles is obtained.

The second stage for designing the LS-PMSG is rotor design. The acrylic material coated with aluminum with a diameter of $30 \mathrm{~cm}$ is selected. That material is then processed to facilitate placement of magnetic core.

Neodymium material is selected to create 10 magnetic poles as depicted in Figure 1.

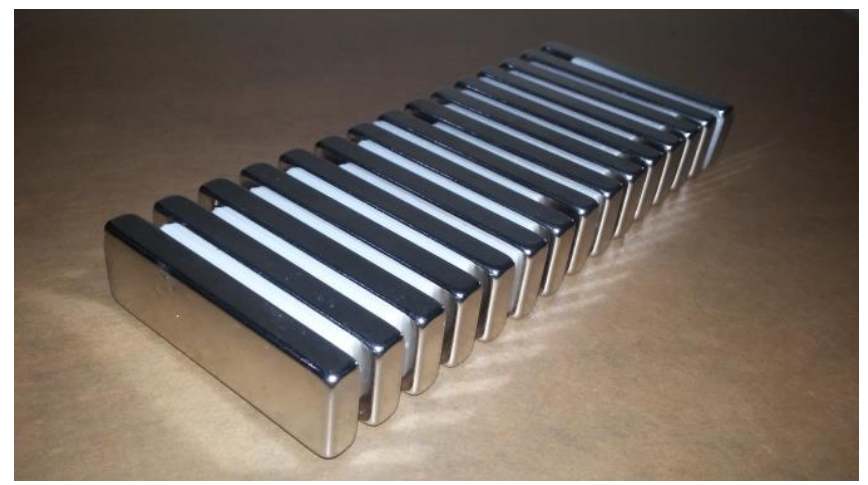

Fig. 1. Neodymium permanent magnet material.

Design and characteristic of the magnetic pole are determined using the following procedures.

A. Determining the Magnetic Flux Density

Magnetic flux density is calculated using the following equation,

$$
B_{\max }=B_{r} \times \frac{L_{m}}{L_{m}+\delta} \quad(T)
$$

Where, $B_{\max }, B_{r}, L_{m}$ and $\delta$ are... respectively.

According to design consideration, it was determined that $\mathrm{B}_{\mathrm{r}} 1.17 \mathrm{~T}$ (Magnet NdFeB type N35) which had $60 \mathrm{~mm}$ length, $15 \mathrm{~mm}$ wide and $5 \mathrm{~mm}$ height. Assuming that the implemented air gap is $3 \mathrm{~mm}$ and implementing (2), the maximum magnetic flux density $\left(B_{\max }\right)$ can be calculated as $0.0538058 \mathrm{~T}$.

\section{B. Determining the Area of Permanent Magnet Poles}

The area of the magnetic pole determines the area of the rotor which has a disc shape. Moreover, the size and shape of stator proportionally follow the size and shape of the rotor to synchronize the axial magnetic flux from the permanent magnet pole at the rotor and magnetic and winding at the stator. The rotor topology of the proposed LS-PMSG is depicted in Figure 2.

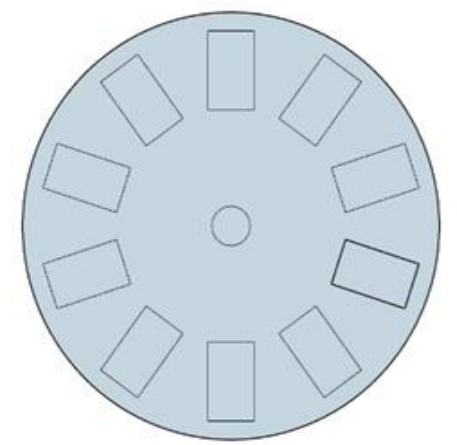

Fig. 2. Design of rotor of LS-PMSG.

Since the rotor side is in a cylindrical disc shape, the magnetic area $\left(A_{m a g n}\right)$ can be calculated as given by the following equation,

$$
A_{\text {magn }}=\frac{\pi\left(r_{0}^{2}-r_{i}^{2}\right)-r f\left(r_{o}-r_{i}\right) N_{m}}{N_{m}} \quad \mathrm{~m}^{2}
$$


Where $r_{\mathrm{o}}$ is the outside magnetic radius, $r_{\mathrm{i}}$ is the inside magnetic radius. While $r f$ and $N_{\mathrm{m}}$ represent the distance between the magnetic pole and number of magnetic poles respectively. From the calculation, the area of each rotor disc is $0.002063466 \mathrm{~m}^{2}$. The values of those parameters are given in Table I.

TABLE I. ROTOR DESIGN PARAMETERS

\begin{tabular}{cc}
\hline Parameters & Values \\
\hline$r_{\mathrm{o}}$ & $13 \mathrm{~cm}$ \\
$r_{\mathrm{i}}$ & $8 \mathrm{~cm}$ \\
$R f$ & $6.5 \mathrm{~cm}$ \\
$N_{\mathrm{m}}$ & 10 \\
\hline
\end{tabular}

\section{Determining the Maximum Flux for Permanent Magnet}

The maximum flux from for permanent magnet pole can be determined from the correlation between maximum flux density $\left(B_{\max }\right)$ and area of the pole $\left(A_{\operatorname{magn}}\right)$ using $(3)$,

$$
\phi_{\max }=A_{\text {magn }} \times B_{\max } \mathrm{Wb}
$$

Where $\phi_{\max }$ represents maximum flux in each permanent magnet pole. From the obtained values of $B_{\max }$ and $A_{\operatorname{magn}}$ from previous calculation procedure, the maximum flux of each permanent magnet pole is $0.0001110265 \mathrm{~Wb}$.

\section{Design of Stator Winding}

Several winding slots at stator side is 10 . The corresponding number is selected according to the number of magnetic poles at the rotor side. The equal number of stator winding slots and permanent magnetic poles is considered to make sure that the circular distance of stator is matched rotor. Moreover, it ensures that all the winding will be fully covered with magnetic flux, providing nominal induction voltage for the generator. The design of stator winding slots is shown in Figure. 3.

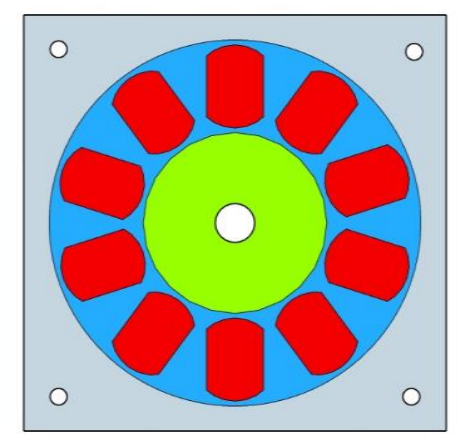

Fig. 1. Fig. 3. Stator winding slots.

After determining the number of slots, the next procedure is determining the number of the stator winding. The number of the stator winding is derived as given by the following equation:

$$
N_{s}=p \times\left(N_{p h} / 2\right)
$$

Where $N_{\mathrm{s}}$ and $N_{\mathrm{ph}}$ represent a number of the stator winding and phase respectively. It is assumed that $N_{\mathrm{ph}}$ is 2 (one phase and one neutral). Therefore, $N_{\mathrm{s}}$ can be determined as 10 . The corresponding value is selected based on a number of poles at the rotor side, the stator size would be proportional with the rotor size. Moreover, it is expected that all the stator winding would be passed by magnetic flux. Number of turns in every slot is then determined. In this paper, 142 turns are selected to provide nominal induction voltage in the output terminal of the machines. The obtained design of rotor and stator with 10 poles is depicted in Figure. 4.
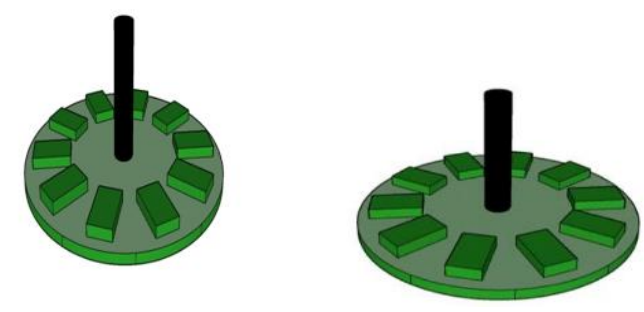

Fig. 4. The 10 poles rotor of LS-PMSG 
The benefit of circular disc type of the proposed LS-PMSG is the flexibility to change the capacity of the machine. As the induced voltage and output power is highly correlated with the amount of magnetic flux, poles, and windings, the output power can be increased proportionally by increasing the number of rotor and stator discs. In this paper, the proposed LS-PMSG employed two stators and three rotor discs in order to generate the designed output power and terminal voltage. The construction of those two stators and three rotor LS-PMSG is shown in Figure. 5.

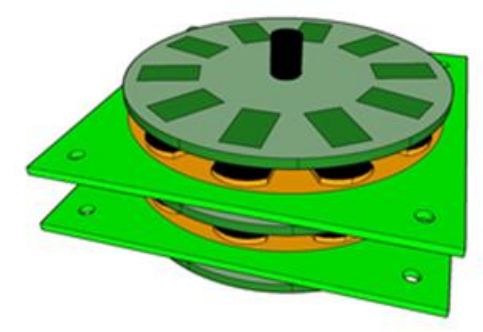

Fig. 5. Two stators and 3 rotor LS-PMSG.

\section{E. Design of Electrical Output Values}

The proposed LS-PMSG is designed to have 10 poles for generating single phase voltage and output power. The magnetic poles are manufactured from permanent magnet NDFeB-35 with $60 \mathrm{~mm}$ x $15 \mathrm{~mm}$ x $5 \mathrm{~mm}$ dimension. Those poles are positioned in circular position according to rotor shape. The design of two stators and three rotors type of LSPMSG using the NDFeB-35 poles is shown in Figure. 6.

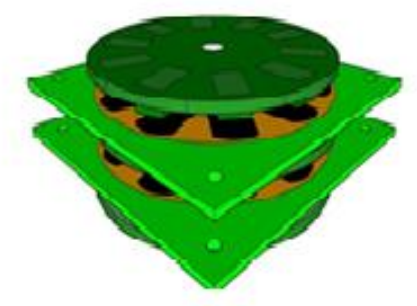

Fig. 6. Single phase LS-PMSG consisting of two stators and three rotors with NDFEB-35 poles.

Induced voltage, generated by two stators and three rotor type of LS-PMSG can be calculated as given by

$$
E_{r m s}=4.44 \times N \times f \times \phi_{\max } \times\left(N_{s} / N_{p h}\right) \quad \text { Volt }
$$

Where $E_{r m s}$ represents rms value of induced voltage from the machine.

Using the obtained parameters as given in the previous sections, the $E_{r m s}$ values of the proposed LS-PMSG is 35 V. While, the rated current of the machine can be calculated using an apparent power equation. From the calculation, the rated current of the machine is $2 \mathrm{~A}$.

As nominal voltage and current have been determined, the rated output power can also be obtained. Assuming that the designed power factor is 0.8 , the rated active power of those single-phase LS-PMSG with two stators and three rotors type is $56 \mathrm{~W}$.

\section{F. Design of Electrical Output Values}

After determining and calculating all the design procedures involving pole, stator, rotor, and electrical output values, the manufacturing stage can be conducted. In this research, the permanent magnet pole is ordered from the other company. Hence it is not involved in the discussion. The permanent magnet pole is depicted in Figure. 7.

First step in manufacturing the LS-PMSG is cutting process to create rotor and stator cylindrical disc shape. All the acrylic material is cut using laser according to the determined size and shape. The acrylic material is shown in Figure. 8. 

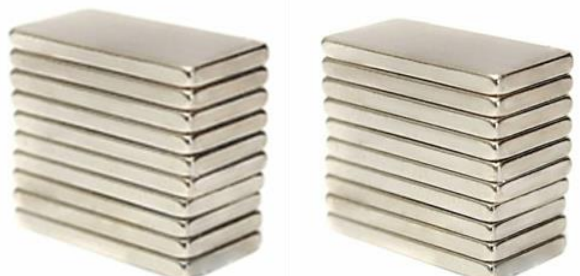

Fig. 7. Permanent magnet for LS-PMSG poles.

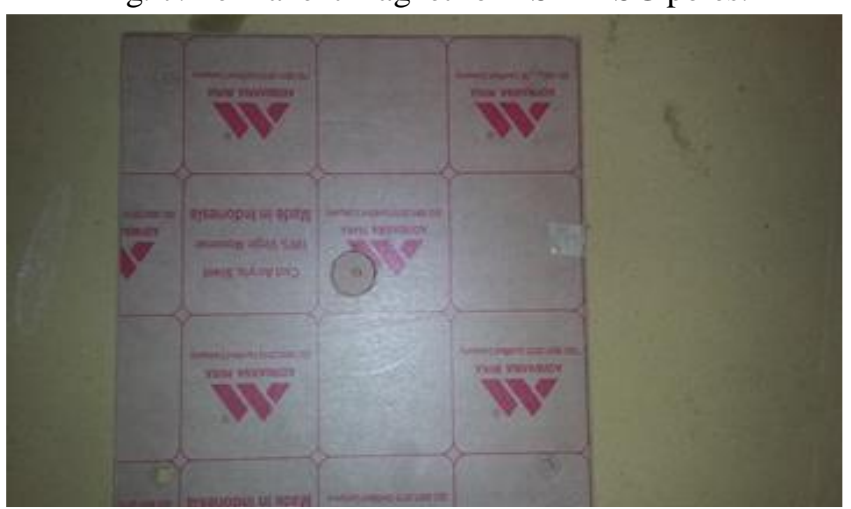

Fig. 8. Acrylic material.

The second step is making the winding as shown in Figure. 9. According to the planning, 142 turns and 20 windings are required to build the proposed machine. The winding is then installed to stator as depicted in Figures 10 and 11.

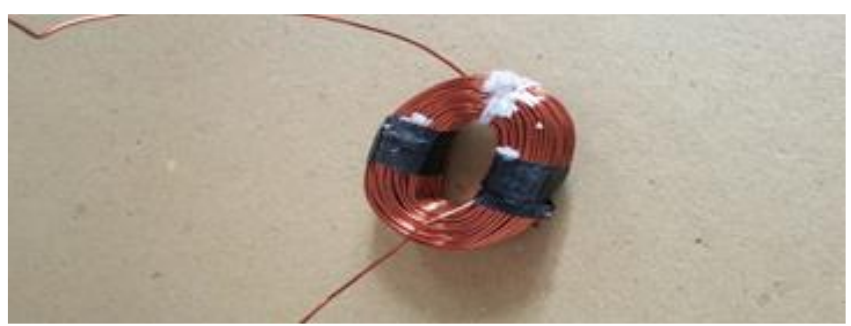

Fig. 9. Winding

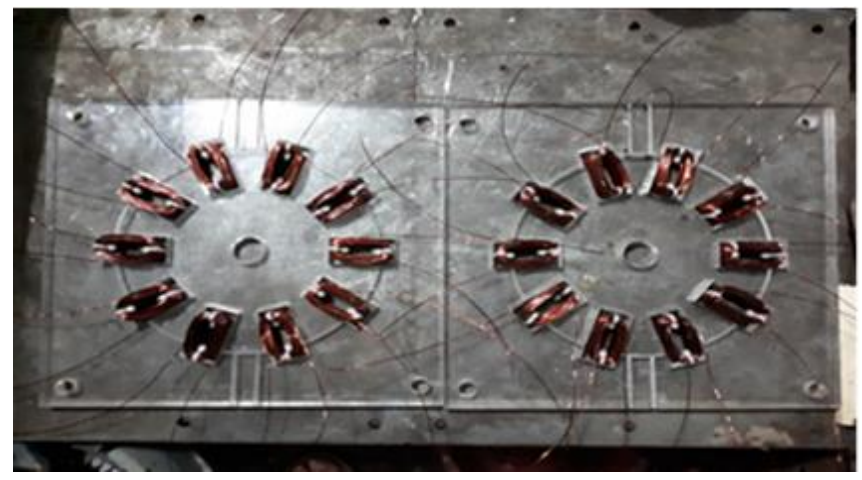

Fig. 10. Installing winding to the stator. 


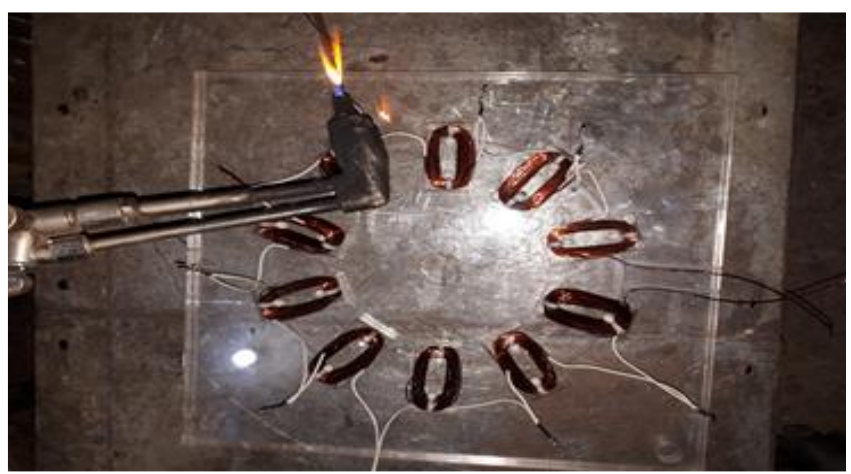

Fig. 11 The winding to the stator installed permanently.

When the stator winding is ready, the next stage is installing rotors in one shaft. The rotors are installed inside the aluminum disc. Installation of three rotors LS-PMSG is depicted in Figure. 12. The stator is then situated in between that three rotor disc to complete the proposed LS-PMSG. The complete manufacture of two stators, three rotors of LS-PMSG is depicted in Figure. 13.

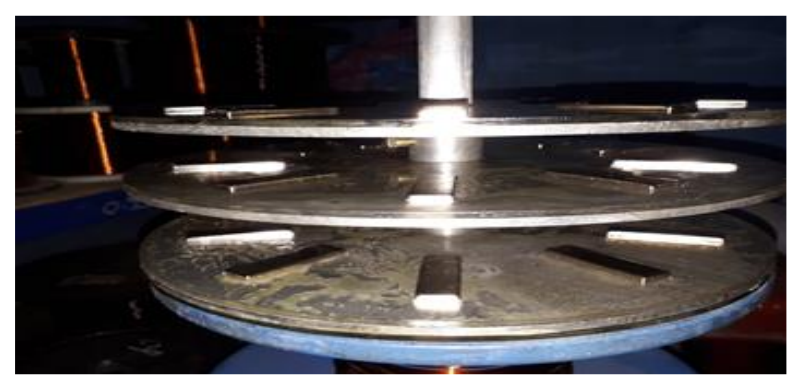

Fig. 12. Rotor installation

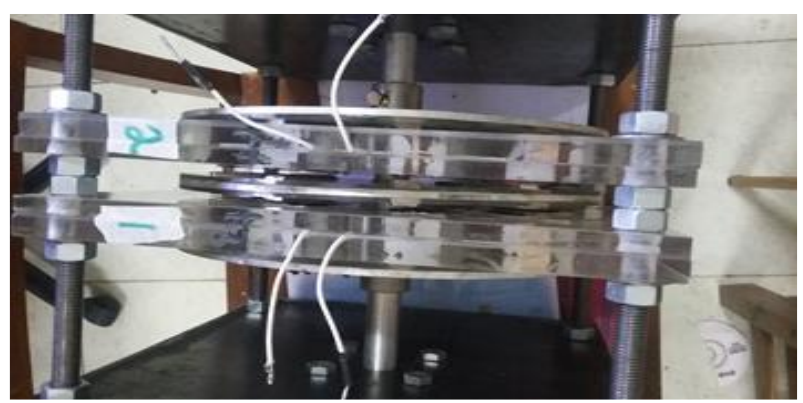

Fig. 13. Complete manufacture of proposed LS-PMSG.

\section{Test And Experimental Results}

The following section provides the test, experimental results of the LS-PMSG. Generator tests are conducted in series and parallel connections under no-load and full load conditions to obtain the characteristic and check the connection between the stators. Under loading condition, the generator is coupled with the prime mover through the variable speed drives to observe generator performance under various speed circumstances. The output voltage, current and power of the generator are then monitored, and electrical characteristic is recorded.

Figures 14 and 15 shows the correlation between the terminal voltage of the generator and operating speed in stator 1 and stator 2 respectively under no-load condition. While the difference of terminal voltage in stator 1 and 2 under no-load condition is shown in Figureure 16. Table 2 represent detailed data during the test. It was monitored that the terminal voltage of the generator is proportionally increased when the operating speed is gradually increased. The terminal voltage is increased to 49.9 Volt under $1000 \mathrm{rpm}$ operational speed. While, under nominal operating speed around $600 \mathrm{rpm}$, the monitored voltage in stator 1 and stator 2 are 29.9 and 28.1 respectively. Under the no-load condition, the generator can handle operational speed above the nominal speed without experiencing overheat.

From several simulations, it was monitored that the proposed LS-PMSG can maintain the frequency around $50 \mathrm{~Hz}$ under various operating speed. It was also observed that the efficiency of the proposed two-stators, three-rotors LS-PMSG in average is around $85.4 \%$. 


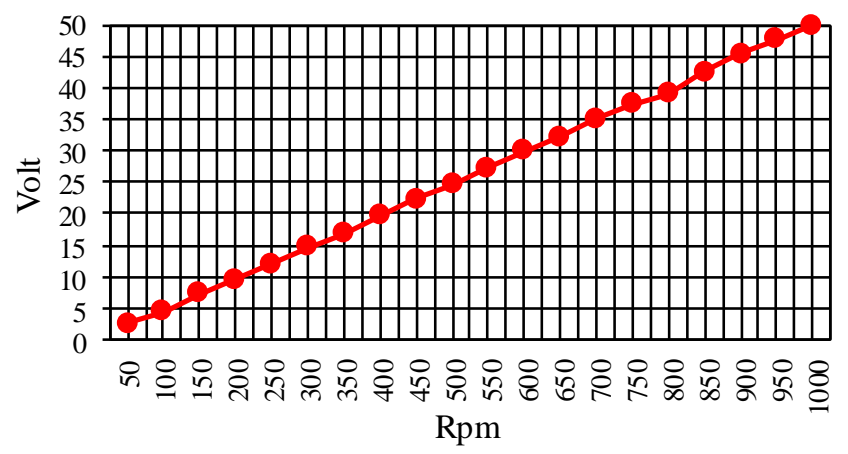

Fig. 14. Terminal voltage of Stator 1 under no-load condition.

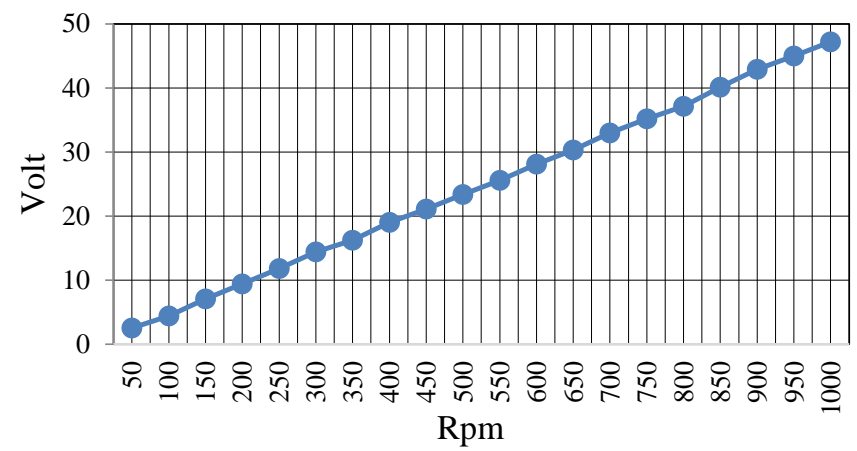

Fig. 15. Terminal voltage in stator 2 under no-load condition.

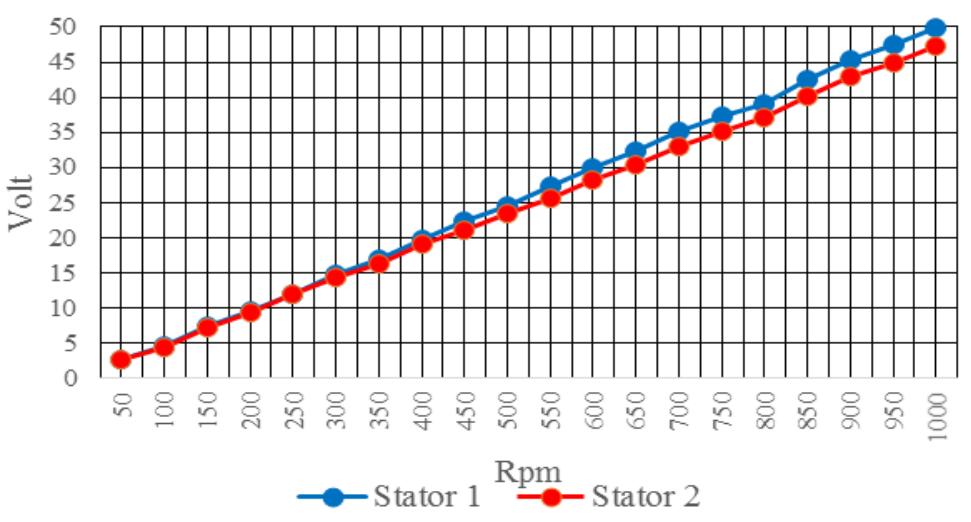

Fig. 16. Terminal voltage in stator 1 and 2 under no-load condition.

Table 2. No-Load Measurement

\begin{tabular}{cccc}
\hline No. & $\begin{array}{c}\text { Speed } \\
(\mathbf{r p m})\end{array}$ & $\begin{array}{c}\text { Stator 1 } \\
\text { Voltage }(\mathbf{V})\end{array}$ & $\begin{array}{c}\text { Stator 2 } \\
\text { Voltage }(\mathbf{V})\end{array}$ \\
\hline 1 & 50 & 2.6 & 2.5 \\
2 & 100 & 4.5 & 4.4 \\
3 & 150 & 7.3 & 7.1 \\
4 & 200 & 9.6 & 9.4 \\
5 & 250 & 12.0 & 11.8 \\
6 & 300 & 14.8 & 14.4 \\
7 & 350 & 16.8 & 16.2 \\
8 & 400 & 19.7 & 19.0 \\
9 & 450 & 22.3 & 21.1 \\
10 & 500 & 24.6 & 23.4 \\
11 & 550 & 27.3 & 25.6 \\
\hline
\end{tabular}




\begin{tabular}{ccccc}
\hline \hline 12 & 600 & 29.9 & \\
\cline { 2 - 4 } 13 & 650 & 32.2 & 30.1 \\
14 & 700 & 35.2 & 33.0 \\
15 & 750 & 37.3 & 35.2 \\
16 & 800 & 39.1 & 37.1 \\
17 & 850 & 42.5 & 40.1 \\
18 & 900 & 45.3 & 42.9 \\
19 & 950 & 47.6 & 45.0 \\
20 & 1000 & 49.9 & 47.2 \\
\hline
\end{tabular}

The second generator test is conducted under loading condition. To simulate the loading scenario, a DC lamp 12 Volt, 21 Watt is considered as a load. Under loading conditions, voltage droop across the winding of the generator was monitored. As the load is connected to the generator, the operating speed is lower than under no-load condition. It was clearly seen that there was a significant difference around 18 Volt was monitored between no-load voltage and loading voltage of the generator. The detailed experimental data both under no-load and loading scenarios are presented in Table II. The voltage profile in stator-1 and stator-2 in series connection under the no-load condition and loading circumstances are shown in Figures 17 and 18 respectively. While the voltage profiles difference between those two scenarios is shown in Figure 19.

TABle 3. NO-LOAd AND LOADING MEASUREMENT FOR SERIES CONNECTION OF GENERATOR.

\begin{tabular}{|c|c|c|c|c|c|c|c|}
\hline \multirow[b]{2}{*}{ NO } & \multirow[b]{2}{*}{ RPM } & \multicolumn{6}{|c|}{ Series Connection } \\
\hline & & 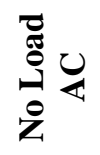 & ט.ّ & 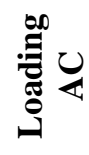 & טِّ & $\vec{E}$ & 育 \\
\hline 1 & 50 & 4,9 & 4,4 & 0 & 0 & - & Off \\
\hline 2 & 100 & 9,4 & 8,7 & 0 & 0 & - & Off \\
\hline 3 & 150 & 14,4 & 12,4 & 0 & 0,2 & - & Off \\
\hline 4 & 200 & 19,3 & 16,9 & 0 & 0,6 & 0,21 & Off \\
\hline 5 & 250 & 24,3 & 21,4 & 0,2 & 1,8 & 0,23 & Dim \\
\hline 6 & 300 & 28,9 & 25,6 & 0,5 & 2,2 & 0,42 & Dim \\
\hline 7 & 350 & 33,3 & 29,4 & 0,9 & 2,7 & 0,54 & Dim \\
\hline 8 & 400 & 39,6 & 35,1 & 1,7 & 3,6 & 0,63 & Dim \\
\hline 9 & 450 & 43,6 & 38,9 & 3,8 & 5,3 & 0,64 & Bright \\
\hline 10 & 500 & 47,7 & 42,2 & 5,8 & 6,2 & 0,74 & Bright \\
\hline 11 & 550 & 53,0 & 50,1 & 8,6 & 7,3 & 0,83 & Bright \\
\hline 12 & 600 & 56,9 & 54,9 & 10,8 & 8,3 & 0,95 & Bright \\
\hline
\end{tabular}

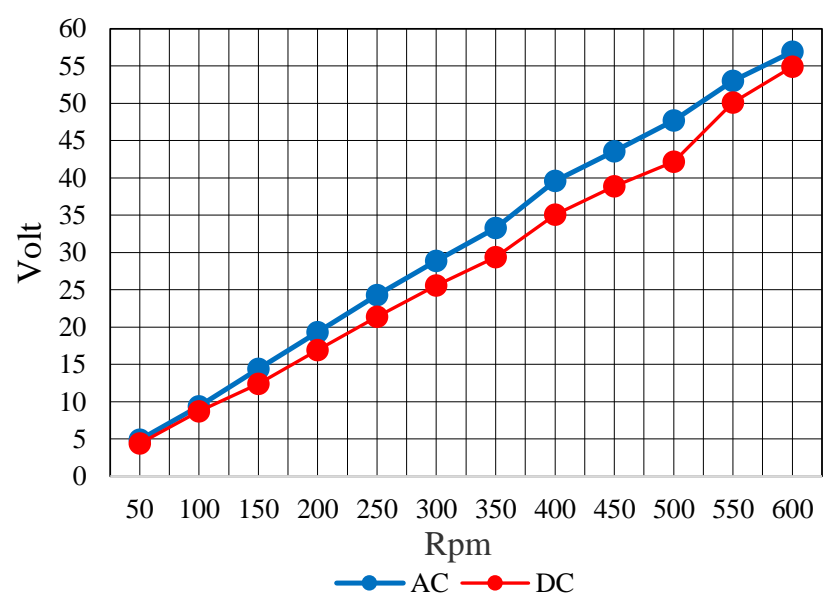

Fig 17. Voltage profiles in series connection under no-load condition. 


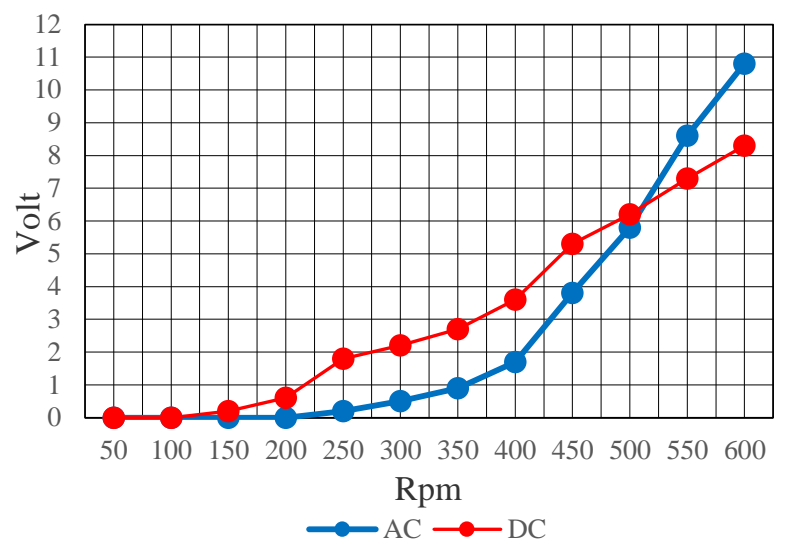

Fig 18. Voltage profiles in series connection under loading condition

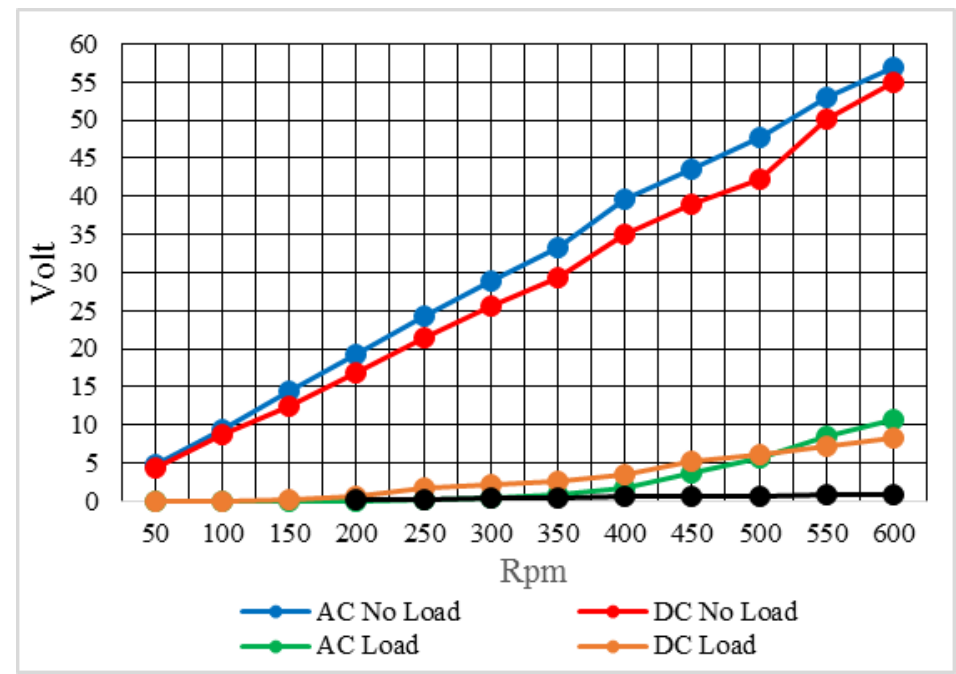

Fig. 19. Voltage profiles difference in series connection under no-load and loading condition.

\section{CONCLUSIONS}

The proposed generator type offers more flexibility in terms of increasing or varying the output power by proportionally adding the number of stator and rotor cylindrical disc. The LS-PMSG with two stator and three rotor configurations can be considered as a viable solution for small scale hydropower plants such as micro and pico-hydropower plant. From the test and experimental results, it was monitored that the proposed type of LS-PMSG is promising and providing a good performance under a wide range of operational speed. Hence, it can be considered for a small-scale power plant to handle the uncertain condition of renewable energy resources.

\section{REFERENCE}

[1] M. M. Ashraf and T. N. Malik. 17.01.2016. "Design of a Three-Phase Multistage Axial Flux Permanent Magnet Generator for Wind Turbine Applications", (accessed $2^{\text {nd }}$ February 2018).

[2] Unknow. Agustus.3.2014. "Desain Axial dan Radial Generator Permanent Magnet, Bagian: https://ugmmagatrika. wordpress.com/2014/08/03/desain-axial-dan-radial-generator-permanent-magnet bagian-i/. (accessed 5th February 2018).

[3] T. Mulyadi "Perbedaan Magnet Permanen dan Magnet Sementara.", http://budisma.net/2016/05/ perbedaan-magnet-permanen-dan-magnetsementara. html (accessed 17 June 2015).

[4] Unknow. Friday, April 17 15."Mengenal Fungsi Rotor", http://komponen-pada-generator.my-free.website/blog/ mengenal-fungsi-rotor/. (accessed 2 February 2018).

[5] Sisilain.net."Pengertian Rotor Dan Stator", http://www.sisilain.net/2011/08/pengertian-rotor-dan-stator.html. (accessed 1 February 2018). 
[6] Unknow."Pengertian Dan Rumus Fluks Magnetik Dalam Fisika”, http://rumusrumus.com/fluks magnetik/. (accessed 2 February 2018).

[7] J. Salsburg. "Direct Drive Wind Turbine Permanent Magnet Generator - Axial Flux Interior Permanent Magnet Topology (AFIPM) http://www.salsburg.com/6phase/Default.html. (accessed 2 February 2018).

[8] H. Prasetijo and W. Winasis. November 2016 "Rancang Bangun Prototipe Generator Arus Bolak - Balik Magnet Permanen Fluks Aksial 1 Fasa Putaran Rendah", https://www.researchgate.net/publication/ 31436338, Rancang_Bangun_Prototipe_Generator_Arus_Bolak - Balik Magnet Permanen Fluks Aksial 1FasaPutaran-Rendah. (accessed 19 March 2018). 